\title{
Desenvolvimento Docente e a Formação de Médicos
}

\author{
Teaching Development and Medical \\ Education
}

Gianna Lepre Perim '; Ively Guimarães AbdallaII; Rinaldo Henrique Aguilar-da-SilvaIII; Jadete Barbosa Lampert ${ }^{I V}$; Regina Celes de Rosa Stella ${ }^{V}$; Nilce Maria da Silva Campos Costa ${ }^{V I *}$

\section{PALAVRAS-CHAVE: \\ - Avaliação de programas. \\ - Educação médica. \\ - Ensino superior. \\ - Docentes.}

Recebido em: 02/07/2008

Reencaminhado em: 17/12/2008

Aprovado em: 19/12/2008

70 REVISTA BRASIEIRA DE EDUCAÇ,̃̄O MÉDICA

\footnotetext{
'Universidade Estadual de Londrina, Paraná, Brasil; Ministério do Esporte, Secretaria Nacional de Esporte Educacional. Distrito Federal, Brasil.

"Universidade Federal de São Paulo, São Paulo, Brasil.

III Faculdade de Medicina de Marília, São Paulo, Brasil.

IV Universidade Federal de Santa Maria, Rio Grande do Sul, Brasil.

${ }^{V}$ Universidade Federal de São Paulo, São Paulo, Brasil.

${ }^{v}$ Universidade Federal de Goiás, Goiás, Brasil.

"Os autores compõem a Comissão de Avaliação das Escolas Médicas da Associação Brasileira de Educação Médica - Caem/Abem.
} 


\section{INTRODUÇÃO}

Na educação médica, é reconhecida a grande influência que a estrutura social, particularmente a organização social dos serviços, exerce sobre a formação dos profissionais de saúde

Embora a educação médica esteja subordinada a regras do campo da educação, é o setor saúde que define seus rumos e sua conexão com a sociedade, em particular por meio da prática médica: "Há importantes estudos mostrando a íntima relação entre educação médica, prática médica e estrutura social. As escolas e os currículos são componentes desses processos mais gerais". ${ }^{1}$

Ao mesmo tempo, as instituições de ensino exercem grande influência na organização dos serviços de saúde, pois interferem na formação dos sujeitos que atuarão no sistema de saúde. De acordo com Almeida², "uma vez que o modo de formar médicos determina a ordem institucional, é esperado que mudanças no primeiro levem a transformações substanciais na forma de organização da educação médica".

Também para Lampert ${ }^{3}$, as reformas do setor saúde estão intrinsecamente ligadas à formação de recursos humanos para a saúde, em especial da categoria médica que mantém a hegemonia ideológica da prática profissional própria do setor. Nessa lógica, os serviços de saúde se organizam para dar respostas aos problemas de saúde e sofrimento da população, e as escolas existem para preparar profissionais, que, atuando nos serviços, dêem respostas aos problemas e às necessidades de saúde.

Nesse sentido, é essencial que a formação profissional em saúde, além de atender às questões educacionais, responda prioritariamente aos problemas e às necessidades de saúde da população. Isto significa uma mudança de paradigma, rompendo efetivamente com o modelo hegemônico do paradigma flexneriano, centrado no diagnóstico e tratamentos das doenças em especialidades.

A aprovação das Diretrizes Curriculares Nacionais do Curso de Graduação em Medicina (DCN) ${ }^{4}$ foi um passo importante na construção da mudança paradigmática da educação médica:

As Diretrizes Curriculares Nacionais (DCN) para os cursos de graduação, na área da saúde, constituemse em mudança paradigmática do processo de educação superior, de um modelo flexneriano, biomédico e curativo para outro, orientado pelo binômio saúde-doença em seus diferentes níveis de atenção, com ações de promoção, prevenção, recuperação e reabilitação da saúde, na perspectiva da integralidade da assistência; de uma dimensão individual para uma dimensão coletiva; de currículos rígidos, compostos por disciplinas cada vez mais fragmentadas, com priorização de atividades teóricas, para currículos flexíveis, modulares, dirigidos para a aquisição de um perfil e respectivas competências profissionais, os quais exigem modernas metodologias de aprendizagem, habilidades e atitudes, além de múltiplos cenários de ensino. ${ }^{5}$

As diretrizes apontam um novo caminho para a formação do médico, prevendo, entre outras questões: a integração de conteúdos e o desenvolvimento de competências e habilidades; a utilização de metodologias ativas de ensino, que levem o estudante a aprender a aprender e a compreender a necessidade da educação permanente; a integração entre ensino, serviços de saúde e comunidade, aproximando o futuro médico da realidade social; a articulação entre ensino, pesquisa, extensão e assistência; e, acima de tudo, a formação de profissionais com autonomia e discernimento para assegurar a integralidade da atenção, além da qualidade e da humanização do atendimento prestado aos indivíduos, famílias e comunidades.

Acreditando ser a avaliação indutora de mudanças e essencial para o acompanhamento responsável da implementação das DCN, a Abem aprovou o Projeto de Avaliação das Tendências de Mudanças no Curso de Graduação das Escolas Médicas Brasileiras ${ }^{6}$ apresentado pela Comissão de Avaliação das Escolas Médicas (Caem/Abem), visando acompanhar a evolução dos currículos de graduação em Medicina. Os eixos definidos abordam as dimensões que integram um curso de graduação na perspectiva da educação médica transformadora, sendo: i) Mundo do Trabalho; ii) Projeto Pedagógico; iii) Abordagem Pedagógica; iv) Cenários da Prática; v) Desenvolvimento Docente.

A proposta sugere a realização da auto-avaliação pelos atores que participam do processo de formação nas escolas médicas, utilizando o instrumento adaptado de Lampert ${ }^{3}$, que permite identificar o estágio em que as escolas se encontram no processo de transformação desejado, que vai do paradigma flexneriano ao paradigma da integralidade, e a partir daí, define sua tipologia. Quanto mais próximo do estágio 3, mais próximo está o curso do que se considera ideal na formação profissional na área médica, atendendo às DCN. Dependendo de onde a escola se situa, pode ser identificada sua tipologia: (a) tradicional; (b) inovadora com tendência tradicional; (c) inovadora com tendência avançada; (d) avançada para as transformações ${ }^{3,6}$.

O instrumento prevê, além da classificação do curso nos estágios de cada vetor e no conjunto dos eixos, a identificação das evidências que comprovam essa classificação. Evidências são aqui entendidas como ações, atividades, projetos, pro- 
gramas, convênios e parcerias (aproximação escola, serviço e comunidade), fóruns de discussão, construção de conhecimentos e outros, todos passíveis de registro documental, que demonstrem e comprovem as mudanças na implementação do currículo no atendimento às DCN para o curso de graduação. Ou seja, exemplos que ressaltem ações predominantes, condizentes com a alternativa escolhida.

Tão importante quanto os resultados é o processo de aplicação do instrumento. A troca de percepções entre os diferentes segmentos envolvidos no curso, favorecida pela busca de consenso, é extremamente rica e possibilita uma revisão permanente das ações em curso, em busca do ideal estabelecido. A aplicação do instrumento em reuniões de avaliação permite ainda a busca constante da responsabilização dos atores quanto às atividades em andamento, discutindo os limites e as dificuldades, o grau de governabilidade em relação aos processos e os passos possíveis para avançar nas mudanças para as transformações.

O presente estudo baseia-se na aplicação do instrumento em 28 escolas médicas que aderiram ao Projeto Caem/Abem em 2006 e realizaram sua auto-avaliação envolvendo os atores sociais que participam do processo de formação, e trata especificamente do eixo Desenvolvimento Docente.

Considerando que as mudanças são essenciais para que os cursos médicos se reorganizem em busca do atendimento às diretrizes, há que se considerar a centralidade que passa a ter o professor no processo de transformação da escola médica.

Essa transformação vai muito além das mudanças curriculares. Não basta reorganizar o currículo, tentando integrar os conteúdos, ou reescrever o projeto pedagógico. Trata-se de romper com a prática pedagógica presente hoje na universidade, embasada excessivamente na transmissão de conhecimentos, para focar a reflexão crítica da produção do conhecimento e do seu uso e da ação social.

Muitas escolas iniciaram seus processos de mudança, a maioria deles, porém, voltada a reformulações curriculares pontuais, com a introdução de metodologias ativas de ensino numa ou noutra disciplina, com mudanças pequenas de cenários e quase nenhum investimento em capacitação docente, impactando de forma muito limitada a formação do médico. Para superar o modelo tradicional, é preciso mais do que isso. É preciso mudar a construção do conhecimento, que está diretamente ligada à prática docente de reprodução e transmissão do conhecimento. Deve-se entender o papel do docente não mais na sua função tradicional de ensinar, de transmitir conhecimento, mas como protagonista das mudanças, que se fazem urgentes.

A complexidade da atuação docente na educação médica voltada ao paradigma da integralidade tem sido discutida por diversos autores ${ }^{3,7-10}$. Nesse novo contexto, não basta a quali- ficação do professor em relação ao conteúdo específico de sua disciplina, o que era suficiente até meados do século passado. Com a ressignificação da ação educativa, é preciso aliar o conhecimento técnico ao fazer pedagógico, de forma que o docente esteja preparado para conceber e implementar soluções pedagógicas adequadas à aprendizagem dos estudantes ${ }^{11}$.

Para Costa ${ }^{8}$, a prática pedagógica é considerada o domínio específico da profissão docente, pois traduz a concepção do professor sobre as funções profissionais e o modo como devem ser desempenhadas.

O professor de medicina, assim como nas demais áreas da docência no ensino superior, não foi preparado para ensinar e, em decorrência disso, sua experiência deriva principalmente de seu conhecimento no campo em que atua. Entendendo-se o exercício docente como uma prática social, a profissionalização do professor passa a ser estratégica no repensar da educação médica em suas dimensões institucional e social. Deve-se compreender o docente como agente transformador, sujeito do processo de ruptura e inovação interna e externa à instituição ${ }^{7}$.

Esse docente, na maioria das vezes médico, provavelmente formado pelo modelo hegemônico centrado no hospital, deverá atuar como educador na nova proposta de formar médicos. Deverá ter capacidade de preparar o estudante para aprender a aprender de forma a acompanhar a evolução do conhecimento; para interagir com os demais profissionais de saúde, atuando com competência em equipes multidisciplinares; para compreender a realidade do sistema único de saúde; e, mais do que isso, para refletir sobre ela, buscando atender às necessidades básicas de saúde dos usuários.

Como fazer com que o docente mude sua postura profissional, acompanhando as inovações didático-pedagógicas? Como esperar que o docente atue na gestão de recursos humanos, na administração universitária, que promova a articulação entre ensino, serviços e a comunidade - enfim, que gerencie o processo de mudanças?

Morin $^{12}$ apresenta questões que traduzem a complexidade do processo:"Como formar educadores nessa nova perspectiva se não reformarmos a educação? Como reformar a educação se não formarmos novos educadores?"

Nesse contexto, considerando que a contribuição do professor de medicina é fundamental para a reorientação da educação médica, ampliando as perspectivas de transformações dos cursos, não há como pensar as mudanças dissociadas do docente. Este precisa de apoio institucional para se desenvolver não apenas no que diz respeito ao conhecimento técnicocientífico e ao processo de ensino-aprendizagem, mas, sobretudo, no que se refere à gestão do curso médico na própria academia e na interação com os serviços e a comunidade. 
Não bastasse a influência da relação entre a prática médica e a docência para as escolas médicas compreenderem a necessidade de estabelecer um processo de educação permanente, centrada no reconhecimento do potencial educativo dos postos de trabalho e na indissociabilidade entre gestão do trabalho e gestão do conhecimento, o fato de o papel do professor ganhar novos contornos na formação de recursos humanos em saúde amplia ainda mais a necessidade de investir na formação e no desenvolvimento docente.

Numa nova configuração pretendida para educação universitária, torna-se relevante o investimento na formação do professor na tradução de competências relacionadas aos valores éticos; a socialização e significação dos conteúdos em diferentes contextos e de sua articulação interdisciplinar, bem como o conhecimento pedagógico e dos processos de investigação que possibilitam o aperfeiçoamento da prática docente. ${ }^{9}$

No projeto de avaliação proposto pela Caem/Abem, o eixo Desenvolvimento Docente aponta a necessidade de o corpo docente contar com referências e apoios institucionais permanentes no cotidiano das atividades didático-pedagógicas. Esse eixo busca identificar a tendência da escola para investir nos aspectos didático-pedagógicos, na atualização técnico-científica, na inter-relação com os serviços, visando constituir parcerias, e na capacitação para a gestão das mudanças na escola. Também identifica as políticas da escola médica em relação ao corpo docente, que é o agente que orienta a formação do médico e define o perfil de assessoramento dos técnico-administrativos para desenvolver suas tarefas, e, para isto, considera os elementos essenciais para que se favoreça o desenvolvimento docente.

\section{MÉTODO}

O instrumento de avaliação de tendências de mudanças das escolas médicas foi respondido pelos atores sociais de cada escola: representantes docentes, discentes e técnicoadministrativos e da comunidade externa local. Cada vetor apresentou três situações alternativas (tradicional, inovadora e avançada para as transformações). As escolas puderam classificar-se em cada um dos três níveis. A tradicional correspondeu a características de um ensino tradicional, flexneriano; a inovadora apresenta inovações, buscando adequar-se às mudanças; e a avançada apresenta características predominantes de mudanças implantadas, que estão de acordo com as DCNs. No mesmo exercício, a cada situação predominante são identificadas a(s) justificativa(s) e a(s) evidência(s) da alternativa escolhida. O instrumento, o método e a descrição dos vetores podem ser consultados no artigo Projeto de avaliação de tendên- cias de mudanças no curso de graduação nas escolas médicas brasileiras (Lampert et al, p.5-18), disponível nesta revista.

Este trabalho apresenta os resultados do eixo Desenvolvimento Docente, no conjunto do curso de graduação, composto dos seguintes vetores: Formação Pedagógica; Atualização Técnico-Científica; Participação nos Serviços de Assistência; e Capacitação Gerencial.

\section{RESULTADOS}

Os resultados apresentados no Quadro 1 e na Gráfico 1 demonstram a percepção dos atores sociais em percentuais de um grupo de 28 escolas médicas brasileiras quanto às tendências de mudança em relação ao eixo Desenvolvimento Docente.

Além da escolha da alternativa predominante em cada vetor, as escolas apresentam justificativas e evidências (Quadros de 2 a 5) que se encaminham para a construção de indicadores que auxiliam na visualização de fragilidades e potencialidades para o Desenvolvimento Docente.

\section{QUADRO 1}

Tendências de mudanças no curso de graduação em um grupo de 28 escolas médicas ao considerarem os vetores do eixo Desenvolvimento Docente e as alternativas/situações

predominantes na percepção dos atores de cada escola - Caem/Abem, 2006

\begin{tabular}{|l|c|c|c|c|c|c|}
\hline \multicolumn{1}{|c|}{ VETORES } & \multicolumn{2}{c|}{$\begin{array}{c}\text { Alternativa } \\
\mathbf{1} \\
\text { tradicional }\end{array}$} & \multicolumn{2}{c|}{$\begin{array}{c}\text { Alternativa } \\
\mathbf{2} \\
\text { inovadora }\end{array}$} & \multicolumn{2}{c|}{$\begin{array}{c}\text { Alternativa } \\
\mathbf{3} \\
\text { avançada }\end{array}$} \\
\hline $\begin{array}{l}\text { Formação } \\
\text { Pedagógica }\end{array}$ & 9 & 32,1 & 11 & 39,3 & 8 & 28,6 \\
\hline $\begin{array}{l}\text { Atualização } \\
\text { Técnico- Científica }\end{array}$ & 6 & 21,4 & 19 & 67,9 & 3 & 10,7 \\
\hline $\begin{array}{l}\text { Participação } \\
\text { nos Serviços de } \\
\text { Assistência }\end{array}$ & 3 & 10,7 & 15 & 53,6 & 10 & 35,7 \\
\hline $\begin{array}{l}\text { Capacitação } \\
\text { Gerencial }\end{array}$ & 12 & 42,9 & 12 & 42,9 & 4 & 14,2 \\
\hline
\end{tabular}

Em relação às alternativas percebidas como predominantes no eixo Desenvolvimento Docente, observa-se, no vetor Formação Pedagógica, que 9 (32,1\%) escolas não oferecem e nem promovem capacitação didático-pedagógica do corpo docente (ou raramente o fazem); 11 (39,3\%) escolas periodicamente oferecem e promovem cursos de orientação didáticopedagógica; e apenas $8(28,6 \%)$ oferecem e exigem capacitação didático-pedagógica de todos os docentes com acompanhamento e desenvolvimento no cotidiano das tarefas didáticopedagógicas (apoio institucionalizado). 


\section{GRÁFICO 1}

O eixo Desenvolvimento Docente e tendências de mudanças em um grupo de 28 escolas médicas brasileiras - Caem/Abem, 2007.

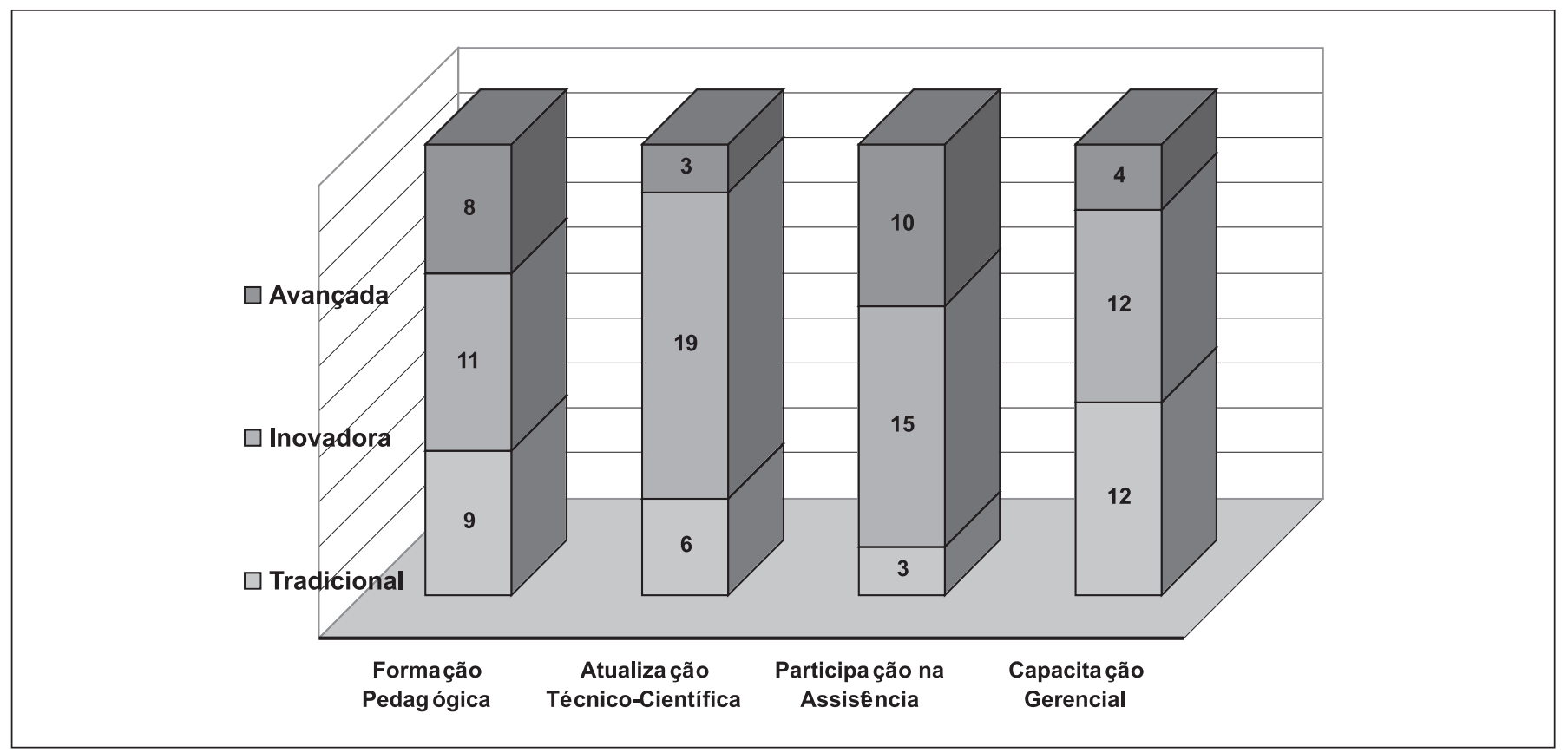

\section{QUADRO 2}

Vetor Formação Pedagógica e a percepção de 28 escolas médicas ao considerarem se a escola oferece ou promove cursos de orientação didático-pedagógica; se o faz esporadicamente ou se isso é uma exigência da política da escola a todos os docentes, com as justificativas e evidências apresentadas

FORMAÇÃO PEDAGÓGICA

\begin{tabular}{|c|c|c|}
\hline Alt. & Justificativas & Evidências \\
\hline \multirow[t]{2}{*}{1} & \multicolumn{2}{|c|}{ Não oferece e nem promove capacitação didático-pedagógica do corpo docente (ou raramente o faz) } \\
\hline & $\begin{array}{l}\text { Inexistência de políticas institucionais de capacitação } \\
\text { docente } \\
\text { Ausência de acompanhamento didático-pedagógico } \\
\text { permanente }\end{array}$ & $\begin{array}{l}\text { Os docentes realizam atividades empiricamente } \\
\text { Baixa participação do corpo docente nas oportunidades oferecidas } \\
\text { A capacitação pedagógica ocorre somente quando o docente } \\
\text { realiza mestrado ou doutorado com disciplinas específicas da área } \\
\text { pedagógica }\end{array}$ \\
\hline \multirow[t]{2}{*}{2} & \multicolumn{2}{|c|}{ Periodicamente oferece e promove cursos de orientação didático-pedagógica } \\
\hline & $\begin{array}{l}\text { Não existe política de apoio pedagógico para docentes, } \\
\text { embora a estrutura curricular exija essa formação } \\
\text { Não existe obrigatoriedade de aperfeiçoamento docente por } \\
\text { parte da instituição nem por parte do professor } \\
\text { Falta de articulação entre a atuação docente e a formação } \\
\text { profissional }\end{array}$ & $\begin{array}{l}\text { Curso básico de formação de tutores } \\
\text { Capacitação em avaliação } \\
\text { Oferta pontual de cursos, palestras, seminários, oficinas e outros } \\
\text { voltados à formação docente e atualização pedagógica } \\
\text { Cursos de capacitação docente na forma de educação permanente e } \\
\text { reflexão sobre a prática } \\
\text { Criação do programa de pós-graduação em educação e saúde com } \\
\text { linha de pesquisa específica em ensino; } \\
\text { Programa de apoio pedagógico institucional obrigatório para } \\
\text { ingressantes; } \\
\text { Cursos anuais de desenvolvimento didático-pedagógico para os } \\
\text { docentes da unidade }\end{array}$ \\
\hline
\end{tabular}


QUADRO 2

Vetor Formação Pedagógica e a percepção de 28 escolas médicas ao considerarem se a escola oferece ou promove cursos de orientação didático-pedagógica; se o faz esporadicamente ou se isso é uma exigência da política da escola a todos os docentes, com as justificativas e evidências apresentadas

FORMAÇÃO PEDAGÓGICA

\begin{tabular}{|c|c|c|}
\hline Alt. & Justificativas & Evidências \\
\hline \multirow[t]{2}{*}{3} & \multicolumn{2}{|c|}{$\begin{array}{l}\text { Oferece e exige capacitação didático-pedagógica de todos os docentes com acompanhamento e desenvolvimento no cotidiano das } \\
\text { tarefas didático-pedagógicas (apoio institucionalizado) }\end{array}$} \\
\hline & $\begin{array}{l}\text { O projeto pedagógico impõe a necessidade de formação } \\
\text { pedagógica } \\
\text { Política institucional e necessidade do curso de adotar } \\
\text { metodologias ativas de ensino-aprendizagem } \\
\text { Existência de norma institucional de capacitação docente } \\
\text { Pouca experiência pedagógica dos docentes }\end{array}$ & $\begin{array}{l}\text { Atividades gerais de capacitação didático-pedagógica: } \\
\text { Cursos em parceria com outras instituições (intercâmbio) } \\
\text { Curso de treinamento de tutores } \\
\text { Curso de planejamento de módulos e construção de problemas } \\
\text { Reuniões de tutores remuneradas e oficinas pedagógicas bimestrais } \\
\text { Cursos de capacitação em metodologias ativas } \\
\text { Curso de pós-graduação lato e stricto sensu em áreas gerais e } \\
\text { especializadas } \\
\text { Iniciativas Institucionais de apoio pedagógico: } \\
\text { Existência de núcleo psicopedagógico, comissão de avaliação do } \\
\text { curso, comissão permanente de avaliação da instituição e comissão de } \\
\text { capacitação docente do curso } \\
\text { Existência de núcleo de apoio pedagógico, encontros regulares com } \\
\text { coordenadores de disciplinas e encontros pedagógicos com curso de } \\
\text { aperfeiçoamento em didática do ensino superior e suas metodologias } \\
\text { As atividade dos docentes são acompanhadas por assessores } \\
\text { pedagógicos } \\
\text { Corpo docente recebe capacitação didático-pedagógica específica } \\
\text { (obrigatória) antes de iniciar as atividades na instituição } \\
\text { Reuniões e discussões sistemáticas sobre as questões pedagógicas }\end{array}$ \\
\hline
\end{tabular}

\section{QUADRO 3}

Vetor Atualização Técnico-Científica e a percepção de 28 escolas médicas ao considerarem se a escola estimula, apóia ou promove, ou não, a atualização técnico-científica dos professores com as justificativas e evidências apresentadas

\begin{tabular}{|c|c|c|}
\hline \multicolumn{3}{|c|}{ ATUALIZAÇÃO TÉCNICO-CIENTÍFICA } \\
\hline \multirow[t]{2}{*}{1} & \multicolumn{2}{|c|}{ Não estimula nem oferece atualização técnico-científica aos professores (ou raramente o faz), deixando por conta do próprio docente } \\
\hline & $\begin{array}{l}\text { Inexistência de espaços de discussão acerca da necessidade de } \\
\text { atualização técnico-científica dos docentes } \\
\text { Ausência de políticas de apoio à participação docente em eventos } \\
\text { científicos } \\
\text { Falta de programas de atualização permanente do docente }\end{array}$ & $\begin{array}{l}\text { Ausência de reflexão e ações referentes à necessidade de } \\
\text { atualização } \\
\text { Falta de disponibilidade dos professores para participar de cursos } \\
\text { em função do volume de trabalho } \\
\text { Falta de estímulo à participação em congressos } \\
\text { Não existe programa de capacitação técnico-científica para } \\
\text { docentes }\end{array}$ \\
\hline \multirow[t]{2}{*}{2} & \multicolumn{2}{|c|}{ Periodicamente apóia e/ou oferece atualização técnico-científica aos professores } \\
\hline & $\begin{array}{l}\text { Ausência ou insuficiência de políticas institucionais } \\
\text { Reconhecimento da necessidade de busca da qualificação } \\
\text { Estímulo à realização de pós-graduação e/ou atualização técnico- } \\
\text { científica (ainda precisa ser aprimorada) } \\
\text { Poucos recursos destinados a estas atividades (na maioria das } \\
\text { vezes, partem do hospital) } \\
\text { Atividades realizadas pelo núcleo psicopedagógico com apoio da } \\
\text { instituição em congressos de educação médica } \\
\text { Interesse da universidade em manter os padrões exigidos pelo } \\
\text { MEC }\end{array}$ & $\begin{array}{l}\text { Apoio eventual à participação em congressos com auxílio } \\
\text { financeiro (falta de apoio à área básica) } \\
\text { Realização de eventos, congressos, fóruns e simpósios } \\
\text { Promoção e apoio a cursos de extensão em parceria com outras } \\
\text { instituições em áreas específicas } \\
\text { Planejamento para afastamento de docentes para qualificação } \\
\text { Oferta de pós-graduação a profissionais da instituição, com } \\
\text { estímulo financeiro ou redução de carga horária sem prejuízo do } \\
\text { salário } \\
\text { Grande round para professores e estudantes com temas } \\
\text { prevalentes e conteúdos atualizados } \\
\text { Estímulo aos professores para publicação (alguns hospitais têm } \\
\text { revistas indexadas) } \\
\text { Inexistência de sistema de substituição do professor que se afasta }\end{array}$ \\
\hline
\end{tabular}




\section{QUADRO 3}

Vetor Atualização Técnico-Científica e a percepção de 28 escolas médicas ao considerarem se a escola estimula, apóia ou promove, ou não, a atualização técnico-científica dos professores com as justificativas e evidências apresentadas

\section{ATUALIZAÇÃO TÉCNICO-CIENTÍFICA}

3 Promove de forma sistemática e exige a atualização dos professores em especial quanto às exigências de necessidades/demandas em saúde

Existência de política institucional

Estímulo aos docentes para estarem incorporados a programas de pós-graduação

Compreensão da importância da atualização

Cursos de atualização lato e stricto sensu

Liberação formal dos profissionais para participação em atividades de capacitação

Política de apoio da participação docente em eventos científicos

\section{QUADRO 4}

Vetor Participação nos Serviços de Assistência e a percepção de 28 escolas médicas ao considerarem se os docentes da escola são estimulados e apoiados a participar dos serviços de assistência; se o pessoal docente e dos serviços tem algum grau de integração; e se há participação da escola no planejamento e avaliação dos serviços e sistema de saúde, com as justificativas e evidências apresentadas

\section{PARTICIPAÇÃO NOS SERVIÇOS DE ASSISTÊNCIA}

1 Não estimula o corpo docente, que, por sua vez, não participa dos serviços e do planejamento do sistema de saúde (municipal, regional) em sua área de influência, e os médicos dos serviços não participam da docência

Falta de integração dos serviços com a academia e vice-versa

Pouco interesse docente em participar das atividades do SUS

Valorização apenas da carga horária de ensino de graduação e de pesquisa pelas IES

Alguns docentes atuam nos serviços, e médicos do serviço participam da docência

Docentes não participam do planejamento do SUS

Eventualmente, docentes são convidados para ocupar cargos de chefia

na secretaria municipal ou estadual de saúde, mas não interagem com a universidade

Participação de hospitais em conselho estadual de saúde

2 Procura estimular os docentes a participar dos serviços e do planejamento do sistema de saúde, o que fazem esporadicamente, e os profissionais de saúde dos serviços eventualmente participam da docência

Boa articulação ensino/serviço com participação bilateral nas atividades (participação do corpo clínico do serviço no corpo docente e vice-versa)

Reconhecimento da importância da atuação da escola nos serviços e estímulo à integração docente assistencial

Previsão da articulação ensino-serviços no projeto pedagógico

Falta de integração dos serviços com a universidade

Falta de estrutura dos serviços para receber os estudantes e os professores

Superficialidade das parcerias entre os serviços e as instituições de ensino

Atividades em unidades de saúde com participação de professores e
Seminários com a participação dos profissionais do serviço e certificação pela participação no processo

Espaços de discussão da integração da academia/serviço Presença de docentes no planejamento da saúde municipal

Integração com as secretarias municipal e estadual de saúde médicos da secretaria de saúde

Chefia das unidades de saúde exercida conjuntamente por professor do curso e médico da secretaria municipal

A integração ocorre menos na ABS e mais nos níveis secundário e terciário Estímulo para que as atividades ocorram com recursos do Promed (cursos de gestão, planejamento e interconsultas) para docentes e profissionais da rede

Poucos professores envolvidos no planejamento dos serviços

Resistência de parte do corpo docente no desenvolvimento de atividades extramuros

3 Estimula os docentes e apóia sua participação no planejamento e avaliação do sistema de saúde em sua área de influência, tem serviços assistenciais integrados com o sistema de saúde, e os médicos dos serviços têm participação na docência

Política institucional e convênio entre escola e município Professores do curso e do serviço atuam efetivamente em todos os níveis Previsão no projeto pedagógico

Incentivo à participação dos profissionais na rede pública
Lei de incentivo municipal para participação dos profissionais da rede na academia

Participação dos docentes nos cargos de gestão nas secretarias e dos profissionais dos serviços na docência

Participação permanente de docentes na gestão de unidades de saúde e representação discente no conselho municipal de saúde;

Convênios com município, reuniões pedagógicas e estágios supervisionados com participação dos médicos do serviço Representação docente no conselho municipal

Ambulatórios integrados à rede com agendamento pela rede, e utilização de referência e contra-referência

Ambulatórios de especialidades que são referência das UBSs

Exigência da escola de que todos os docentes exerçam atividade de atenção à saúde 


\section{OUADRO 5}

Vetor Capacitação Gerencial e a percepção de 28 escolas médicas ao considerarem se a escola promove e/ou reconhece a importância da capacitação gerencial dos docentes que assumem cargos administrativos/diretivos ou se isso é feito de forma empírica e fundada em experiência própria (disciplina, departamento, direção de escola, de hospital universitário, etc.), com as justificativas e evidências apresentadas

\begin{tabular}{|c|c|c|}
\hline \multicolumn{3}{|c|}{ CAPACITAÇÃO GERENCIAL } \\
\hline \multirow[t]{2}{*}{1} & \multicolumn{2}{|c|}{$\begin{array}{l}\text { Não promove capacitação gerencial dos docentes que assumem cargos administrativos institucionais de forma empírica e fundada em } \\
\text { experiência própria (disciplina, departamento, direção de escola, de hospital universitário, etc.) }\end{array}$} \\
\hline & $\begin{array}{l}\text { Falta de valorização institucional das atividades de gestão } \\
\text { Ausência de programas de capacitação gerencial }\end{array}$ & $\begin{array}{l}\text { Inexistência de capacitação em ciências administrativas } \\
\text { Participação de docentes sem formação específica na administração } \\
\text { dos cursos } \\
\text { Os docentes aprendem na prática } \\
\text { Poucos docentes com capacidade gerencial }\end{array}$ \\
\hline \multirow[t]{2}{*}{2} & \multicolumn{2}{|c|}{$\begin{array}{l}\text { Não promove mas reconhece a importância da capacitação gerencial, tendo docentes que assumem cargos administrativos } \\
\text { institucionais com algum conhecimento de ciências administrativas e que buscam imprimir estilo gerencial participativo entre os } \\
\text { segmentos docente, discente e técnico-administrativo }\end{array}$} \\
\hline & $\begin{array}{l}\text { Reconhecimento da importância da capacitação gerencial sem } \\
\text { ação correspondente } \\
\text { Contratação de profissionais capacitados para a função } \\
\text { gerencial } \\
\text { Estímulo à participação gerencial e administrativa em } \\
\text { documentos e treinamento } \\
\text { Não existe política de incentivo à capacitação gerencial no } \\
\text { curso } \\
\text { Excessiva carga de trabalho para quem assume as funções de } \\
\text { gerenciamento do curso }\end{array}$ & $\begin{array}{l}\text { Estrutura matricial para gestão do curso } \\
\text { Ampla representação docente e discente nas comissões } \\
\text { Comissões formadas para gerenciamento (apoio) } \\
\text { Realização de fóruns periódicos } \\
\text { Treinamento em gestão institucional do diretor acadêmico da escola } \\
\text { Resistências dos docentes a esta qualificação } \\
\text { A capacitação gerencial depende exclusivamente da iniciativa de cada } \\
\text { docente }\end{array}$ \\
\hline \multirow[t]{2}{*}{3} & \multicolumn{2}{|c|}{$\begin{array}{l}\text { Promove capacitação gerencial e dispõe de docentes que assumem cargos administrativos institucionais com bom conhecimento de } \\
\text { ciências administrativas, liderando programas, buscando assessorar-se de acordo com as necessidades identificadas e proporcionando } \\
\text { participação ativa e responsabilização dos segmentos docente, discente e técnico-administrativo nas decisões, processos, resultados e } \\
\text { avaliações institucionais }\end{array}$} \\
\hline & $\begin{array}{l}\text { Necessidade de profissionalização dos docentes gestores } \\
\text { Exigência de que os gestores se capacitem }\end{array}$ & $\begin{array}{l}\text { Curso de capacitação para coordenadores de curso e chefes de } \\
\text { departamentos } \\
\text { Curso de capacitação com uso de ambiente virtual } \\
\text { Curso de capacitação em gestão universitária } \\
\text { Criação de uma câmara de gestão na universidade } \\
\text { Promoção de cursos de gestão e planejamento estratégico com } \\
\text { parcerias de outras instituições da área gerencial }\end{array}$ \\
\hline
\end{tabular}

Quanto ao vetor Atualização Técnico-Científica, 6 (21,4\%) escolas não estimulam nem oferecem essa atualização aos professores (ou raramente o fazem), deixando-a por conta do próprio docente; outras 19 (67,9\%) escolas periodicamente apóiam e/ou oferecem atualização aos professores; e apenas $3(10,7 \%)$ escolas promovem de forma sistemática e exigem a atualização dos professores, em especial quanto às exigências das necessidades/demandas em saúde.

No vetor Participação nos Serviços de Assistência, nesse grupo de escolas, apenas 3 (10,7\%) não estimulam o corpo docente, que, por sua vez, não participa dos serviços e do planejamento do sistema de saúde (municipal, regional) em sua área de influência, e os médicos dos serviços não participam da docência; 15 (53,6\%) escolas procuram estimular os docentes a participar dos serviços e do planejamento do sistema de saúde, o que fazem esporadic-amente, e os profissionais de saúde dos serviços eventualmente participam da docência; e 10 (35,7\%) escolas estimulam os docentes e apóiam sua participação no planejamento e avaliação do sistema de saúde em sua área de influência, têm serviços assistenciais integrados com o sistema de saúde, e os médicos dos serviços têm participação na docência.

No vetor Capacitação Gerencial, do grupo de escolas, 12 $(42,9 \%)$ não promovem capacitação gerencial dos docentes, que assumem cargos administrativos institucionais de forma empírica e fundada em experiência própria (disciplina, departamento, direção de escola, de hospital universitário etc.); 


\section{GRÁFICO 2}

O eixo Desenvolvimento Docente e a tipologia de tendências de mudanças em um grupo de 28 escolas médicas brasileiras e a percepção de cada escola quanto à alternativa predominante - Caem/Abem, 2007.

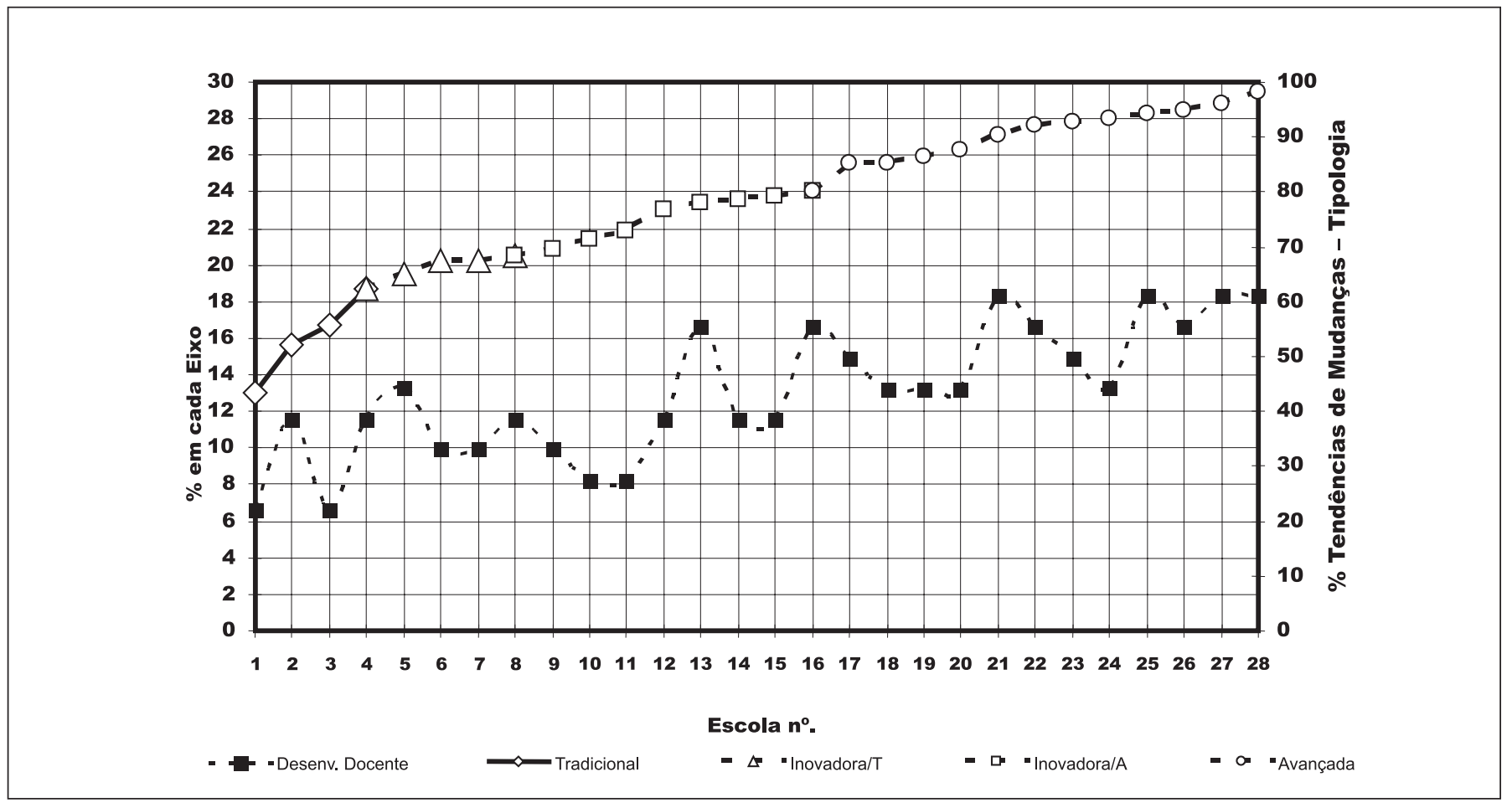

outras $12(42,9 \%)$ escolas não promovem, mas reconhecem a importância da capacitação gerencial, tendo docentes que assumem cargos administrativos institucionais com algum conhecimento de ciências administrativas e buscam imprimir estilo gerencial participativo entre os segmentos docente, discente e técnico-administrativo; e apenas 4 (14,2\%) escolas promovem capacitação gerencial e possuem docentes que assumem cargos administrativos institucionais com bom conhecimento de ciências administrativas, liderando programas, buscando assessorar-se de acordo com as necessidades identificadas e proporcionando participação ativa e responsabilização dos segmentos docente, discente e técnico-administrativo nas decisões, processos, resultados e avaliações institucionais.

Como se verifica no Gráfico 2, o eixo Desenvolvimento Docente apresenta grande variabilidade. Cada eixo corresponde a $20 \%$ do total, sendo que o Desenvolvimento Docente é o único que atinge percentual abaixo de $15 \%$ no geral, correspondendo a 12,7\%. Quando se compara este eixo aos demais (Gráfico 3), percebe-se o quanto se distancia na curva, encontrando-se bem abaixo de todos os outros.

\section{DISCUSSÃO}

As tendências de mudanças no eixo Desenvolvimento Docente, na maioria das escolas analisadas, são menos significativas que nos demais eixos. Nenhuma escola percebe o Desenvolvimento Docente integralmente no nível 3, o que indica uma fragilidade para atender às diretrizes de forma plena. Mais de uma escola se percebe totalmente no nível 1, ou seja, em todos os vetores se considera tradicional. As escolas que foram mais críticas em sua auto-avaliação reconhecem a fragilidade desse eixo no contexto das mudanças.

Considerando a tipologia das 28 escolas obtida a partir dos 5 eixos e a pontuação obtida no eixo Desenvolvimento Docente, 14 se consideram tradicionais em todos os vetores do eixo, o que representa $50 \%$ do total, e as demais se dividem entre as outras alternativas; 6 se percebem na alternativa 2 , inovadora e 8 na alternativa 3 , avançada, ocorrendo contraditoriamente o inverso do que se observa no perfil de tipologias do grupo das escolas.

Mesmo as escolas que resultaram de tipologia avançada (13) apresentam esta contradição quando analisado o eixo Desenvolvimento Docente de forma isolada. 


\section{GRÁFICO 3}

Tipologia de tendências de mudanças em um grupo de 28 escolas médicas brasileiras e a percepção de cada escola quanto à alternativa predominante nos cinco eixos - Caem/Abem, 2007.

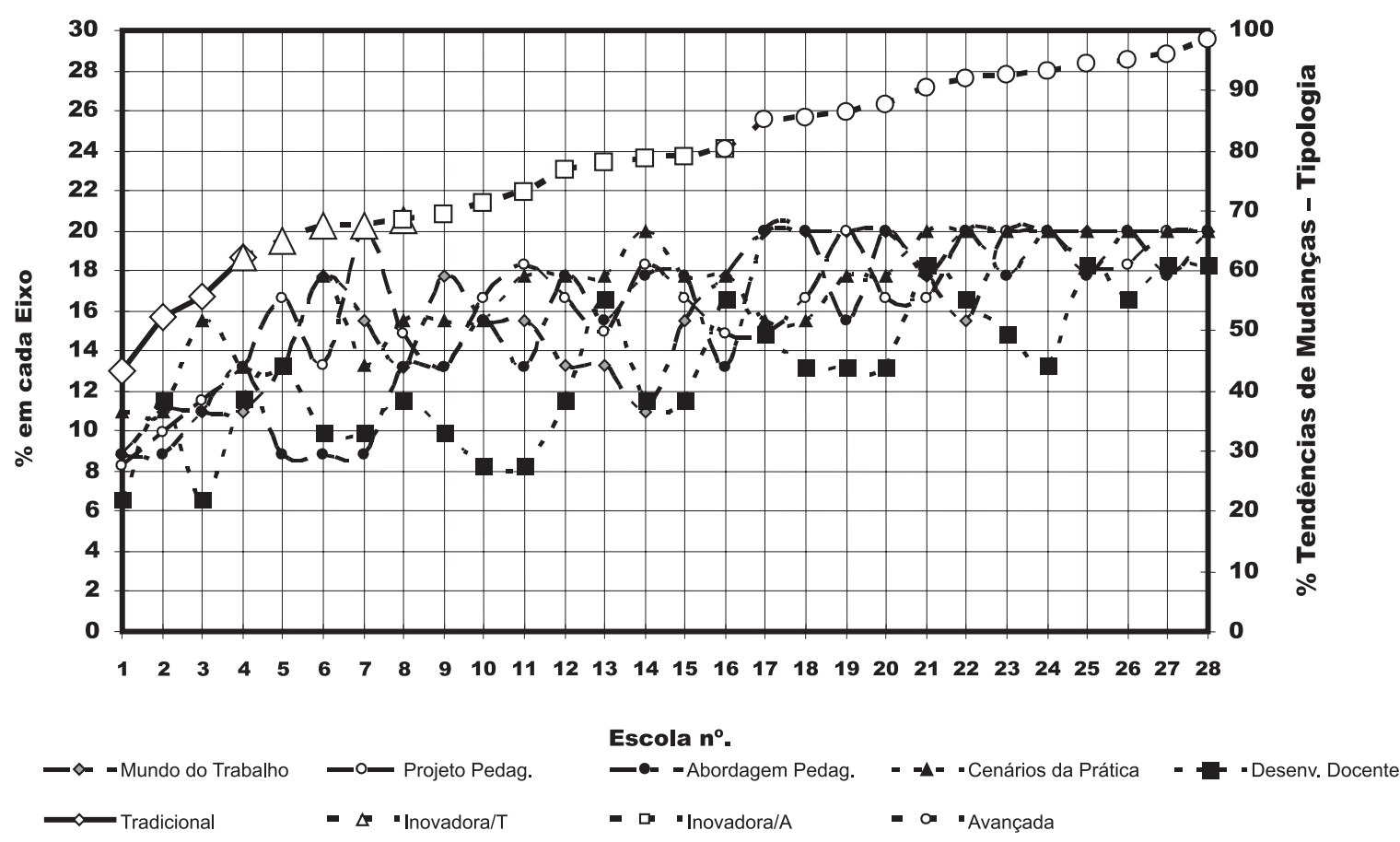

Em relação à percepção do conjunto de escolas para cada um dos vetores, a maioria entende que as escolas não oferecem nem promovem a formação pedagógica do corpo docente; apóiam e/ou oferecem periodicamente a atualização técnico-científica dos docentes; procuram estimular os docentes a participar dos serviços, embora ainda de forma esporádica; e não promovem, mas reconhecem a importância da capacitação gerencial do corpo docente.

Entre os vetores, o que mais avança é a Participação nos Serviços de Assistência, em que 10 escolas se consideram avançadas e 15, inovadoras, sendo que apenas 3 se percebem como tradicionais. É importante observar que esse vetor tem uma relação direta com o eixo Cenários da Prática, no qual os vetores Local de Prática e Participação Discente são os que mais têm avançado na percepção das escolas.

Já o vetor Capacitação Gerencial é aquele em que menos se percebem mudanças, sendo que apenas 4 escolas se consideram avançadas, e as demais se dividem entre tradicionais (12) e inovadoras (12).

Considerando os resultados do conjunto das EMBs, as principais evidências apontadas em cada um dos vetores do eixo Desenvolvimento Docente são: (a) Formação Pedagógica: inexistência de políticas institucionais de capacitação docente; ausência de acompanhamento didático-pedagógico permanente; falta de articulação entre a atuação docente e a formação profissional;

(b) Atualização Técnico-Científica: inexistência de espaços de discussão acerca da necessidade de atualização técnicocientífica dos docentes; ausência de políticas de apoio à participação docente em eventos científicos; falta de programas de atualização permanente do docente;

(c) Participação nos Serviços de Assistência: falta de integração dos serviços com a academia e vice-versa; pouco interesse docente em participar das atividades do SUS; falta de estrutura dos serviços para receber os estudantes e os professores; superficialidade das parcerias entre os serviços e as instituições de ensino; resistência de parte do corpo docente no desenvolvimento de atividades junto aos serviços e comunidade;

(d) Capacitação Gerencial: falta de valorização institucional das atividades de gestão; ausência de programas de capacitação gerencial; participação gerencial de docentes sem formação em ciências administrativas; excessiva carga de trabalho para quem assume as funções de gerenciamento no curso. 
Segundo Lampert”, "capacitação, mais do que treinamento, implica mudanças de referências teórico-metodológicas e de pressupostos arraigados sobre o ensino: o papel do docente e a prática médica."

Para muitos autores, o professor de medicina considera a docência uma atividade secundária à profissão médica ${ }^{3,7,8}$, e isso é uma conseqüência da pouca valorização das atividades de ensino nas instituições de ensino superior, em contraponto à supervalorização da pesquisa. Os próprios critérios de seleção para a escolha de professores para atuar na escola médica ainda consideram fundamentalmente a competência na área técnica ${ }^{1,7,9}$

Outra questão a considerar é que não há uma identidade profissional para o médico como professor, diferentemente do que ocorre com a área específica de sua profissão. Segundo Campos et al. ${ }^{9}$, a formação dessa identidade profissional se processa em dois níveis: interno e externo - externamente, pela aquisição de novas informações e pela participação em um novo conjunto social; internamente, requer uma transformação, um autoconceito subjetivo que pode se exteriorizar na socialização profissional, que deve ser favorecida pela convivência com outros profissionais que realizam tarefas semelhantes. Para esses autores, os programas de desenvolvimento docente podem contribuir muito com a construção dessa identidade e para a profissionalização da docência em escolas médicas. Podem ainda potencializar seus efeitos, uma vez que favorecem a aproximação desses profissionais, podendo, inclusive, motivar a formação de redes de educadores médicos ${ }^{9}$.

Em que medida os afazeres docentes estão comprometidos com a constituição de sólidas bases científicas para o exercício da medicina e com a formação profissional assentada na interlocução entre diferentes olhares e saberes sobre o processo de saúde-doença-cuidado em cenários diversos é a preocupação trazida por Ribeiro ${ }^{13}$.

As pesquisas realizadas na educação médica têm demonstrado a urgência em estabelecer uma cultura de formação docente como processo de educação permanente ${ }^{7}$.

O desenvolvimento docente ganha importância na atuação da escola médica, especialmente em sua missão de preparar profissionais que contribuam para a reorientação do sistema de saúde. De acordo com Campos et al. ${ }^{9}$, a literatura dispõe de farta evidência que demonstra a importância de programas de desenvolvimento docente no desencadeamento e estabelecimento de mudanças curriculares, podendo constituir o principal desencadeador dessas mudanças.

Mais do que cursos de atualização, conhecimento técnico-científico, teorias de aprendizagem e critérios de avaliação, que se limitam a questões didático-pedagógicas, é necessária uma compreensão diferenciada da educação médica, o que amplia o entendimento da própria docência médica:

[...] para além da organização das situações de aprendizagem (ensino e assistência), da produção de conhecimento (pesquisa); ser docente requer uma inserção comprometida com o gerenciamento da escola médica, assumindo opções no âmbito político-curricular.?

Segundo Ribeiro ${ }^{13}$, uma proposta metodológica de educação permanente ideal na área da saúde deve reunir conceitos desenvolvidos no campo da educação da administração de recursos humanos e da gestão de serviços. Assim, poderá contribuir de forma mais efetiva com o desenvolvimento docente, que, de acordo com Batista e Batista ${ }^{7}$, especificamente para a medicina, deve ir além:

O desenvolvimento docente em medicina requer a construção de uma cultura efetiva de educação permanente e de integração das várias atividades docentes no desafio de responder às transformações sociais e do mundo do trabalho [...]. As exigências em relação ao aperfeiçoamento docente devem ser acompanhadas de vontade política, de elaboração de programas efetivos, de investimento econômico e de melhoria das condições de trabalho. A elaboração e implementação de programas de formação e avaliação docente devem considerar a complexidade das relações dentro das instituições e destas com a sociedade, estruturando instrumentos para dimensionar o impacto das medidas implementadas e seu valor para subsidiar a tomada de decisões no contexto do ensino médico.

É preciso reconsiderar os conhecimentos necessários à atuação docente, se objetivamos uma educação médica comprometida com a formação de profissionais qualificados do ponto de vista científico e humanístico para que possam cumprir seu papel na sociedade ${ }^{8}$.

Este é um processo permanente de mudança que precisa ser acompanhado e avaliado. Não uma avaliação técnica de resultados, mas uma avaliação educativa, que tenha como foco central a formação humana, que, para Dias Sobrinho ${ }^{14}$, "comporta várias dimensões: técnica, ética, política, social, enfim, tudo o que tem a ver com o desenvolvimento material e espiritual do indivíduo e da sociedade".

\section{CONSIDERAÇÕES FINAIS}

Analisando-se os resultados do eixo Desenvolvimento Docente no contexto das tendências de mudanças nas escolas médicas, percebe-se que a maioria se mostra com carac- 
terísticas tradicionais, divergindo das tendências observadas nos demais eixos. Tem-se clara na literatura a influência dos aspectos analisados neste eixo no processo de mudanças das escolas, que mostram o impacto das deficiências no desenvolvimento docente nos demais eixos.

Para as 28 escolas, o eixo Desenvolvimento Docente é o que se encontra mais distante do preconizado pelas DCN. Fica evidenciado que o investimento na capacitação docente, desde a formação didático-pedagógica, a atualização científica até a capacidade gerencial, é fundamental para dar suporte às mudanças implementadas pelas escolas e para garantir a interação entre ensino, serviços e comunidade na formação do médico nessa nova perspectiva.

Observando-se as tendências das escolas para investir nos aspectos didático-pedagógicos, técnico-científicos, de gestão e de interação com os serviços e a comunidade, caracterizam-se as políticas da escola médica em relação ao corpo docente:

- Investimentos em capacitação, em educação permanente/continuada, em pós-graduação, em formação gerencial, entre outros;

- Políticas de participação em congressos, seminários, oficinas de atualização de participação em comissões externas, da política de saúde local;

- Plano de incentivo à capacitação docente, em nível de pós-graduação;

- Núcleo de apoio pedagógico;

- Atuação de profissionais da rede na escola e de professores da escola na rede;

- Sensilbilização e instrumentalização do corpo docente para as mudanças;

- Capacitação docente permanente e em vários níveis.

Analisando-se as escolas de modo geral e identificando-se as que mais avançaram nas mudanças em todos os eixos, verifica-se uma postura diferenciada em relação ao desenvolvimento docente. Este se deu onde se encontram as seguintes características:

- Relações democráticas entre serviços, universidade e comunidade;

- A realidade como eixo articulador do ensino, da pesquisa e da prestação de serviços;

- Desenvolvimento de competências específicas para o docente atuar nos vários cenários onde se dá o processo de ensino-aprendizagem;

- Participação de docentes no planejamento e avaliação do sistema de saúde.

Ainda há um longo caminho a percorrer para que as escolas médicas avancem no conjunto dos eixos que compõem as
DCN. Isto só se dará quando for superada a fase de inovação em que se encontram muitas escolas, introduzindo isoladamente alguns dos componentes propostos pelas diretrizes, tais como a prática fora do âmbito do hospital-escola, as metodologias ativas de ensino-aprendizagem, a interdisciplinaridade e a produção de conhecimentos articulada com os serviços.

Para o alcance dos pressupostos trazidos pelas Diretrizes Curriculares, a integração entre ensino, serviços e comunidade ainda deve ser superada pela possibilidade real de transformação da prática pedagógica, da prática dos serviços e da prática social. $\mathrm{O}$ estudo evidencia que qualquer avanço nesse sentido perpassa o repensar da formação docente na educação médica.

\section{REFERÊNCIAS}

1. Feuerwerker L. Mudanças na educação médica: os casos de Londrina e Marília. São Paulo: Hucitec; Rio de Janeiro: Abem; 2002.

2. Almeida M. Educação médica e saúde: possibilidades de mudança. Londrina: Ed. UEL. Rio de Janeiro: Abem; 1999.

3. Lampert JB. Tendências de mudanças na formação médica no Brasil. Tipologia de escolas. São Paulo: Hucitec; Rio de Janeiro: Abem; 2002.

4. Brasil. Ministério da Educação. Conselho Nacional de Educação. Câmara de Ensino Superior. Resolução CNE/ CES no 4, de 07 de novembro de 2001. Institui as diretrizes curriculares nacionais do curso de graduação em medicina. Brasília; 2001.

5. Stella RCR. A prática médica no contexto das diretrizes curriculares nacionais para o curso de medicina. São Paulo: S.1; 2007.14p.

6. Associação Brasileira de Educação Médica. Comissão de Avaliação das Escolas Médicas. Projeto avaliação de tendências de mudanças nos cursos de graduação das escolas médicas brasileiras. [online]. [Acesso em: 2006]. Disponível em: http:/ / www.abem-educmec.org.br

7. Batista NA, Batista SH. Desenvolvimento docente em medicina: a prática como elemento estruturante. In: Batista NA, Batista SH, Abdalla YG, org. Ensino em saúde: visitando conceitos e práticas. São Paulo: Arte \& Ciência; 2005. p. 303-16.

8. Costa NMSC. Docência no ensino médico: por que é tão difícil mudar? Rev Bras Educ Med. 2007;31:21-30.

9. Campos HH, Campos JJB, Faria MJS, Barbosa PFA, Araújo MNT. Programas de desenvolvimento docente em escolas médicas: oportunidades e perspectivas: mais do que uma necessidade. Cadernos Abem; 2007;3:34-8.

10. Carabetta Jr V, Cury MC da FS. A contribuição da coordenação pedagógica na Escola de Medicina. Rev Bras Educ Méd. 2007;31:44-51. 
11. Anastasiou L das CG. Construindo a docência no ensino superior: relação entre saberes pedagógicos e saberes científicos. In: Rosa DEG, Souza VC. Didática e práticas de ensino: interfaces com diferentes saberes e lugares formativos. Rio de Janeiro: DP\&A; Goiânia: Alternativa; 2002. p.173-87.

12. Morin E. Complexidade e transdisciplinaridade: a reforma da universidade e do ensino fundamental. Tradução de Edgard de A. Carvalho. Natal: EDUFRN; 1999.

13. Ribeiro ECO. Educação permanente em saúde. In: Marins JJN, Rego S, Lampert JB, Araújo JGC (Org.). Educação médica em transformação: instrumentos para a construção de novas realidades. São Paulo: Hucitec; Rio de Janeiro: Abem; 2004. p.285-303.
14. Dias Sobrinho J. Universidade e avaliação: entre a ética e o mercado. Florianópolis: Insular; 2002.

Apoio: Convênio no 1614/2007 - Fundo Nacional de Saúde/ MS.

\section{CONFLITOS DE INTERESSE}

Declarou não haver.

\section{ENDEREÇO PARA CORRESPONDÊNCIA}

Gianna Lepre Perim

SQS 307 - Bloco H - apt ${ }^{\circ} 104$

CEP. 70354-080 - Brasília - DF

E-mail: gianna.perim@esporte.gov.br 